\title{
Strategi Pendidik dalam Menumbuhkan Karakter Jujur Pada Anak Usia Dini
}

\author{
Yoyo Zakaria Ansori ${ }^{\bowtie}$ \\ Pendidikan Guru Sekolah Dasar, Universitas Majalengka, Indonesia(1) \\ DOI: $10.31004 /$ obsesi.v6i1.1208
}

\begin{abstract}
Abstrak
Perilaku tidak jujur anak dapat ditemukan pada usia dua sampai tiga tahun dengan maksud untuk menyembunyikan perilaku mereka yang salah seperti belum mampu merawat dan menjaga mainan milik sekolah maupun anak mengambil barang milik sekolah. Kondisi tersebut akan berkembang dan menjadi karakter asli kalau terjadi pembiaran. Karena keberhasilan mewujudkan pembinaan karakter di usia itu merupakan parameter untuk membangun karakter siswa pada jenjang selanjutnya. Tujuan melakukan penulisan artikel ini untuk menganalisa dan menggambarkan komponen komponen mendidik siswa agar berperilaku jujur. Pendekatan kualitatif digunakan dalam penelitian sedangkan untuk memberikan beragam pemikiran dari para ahli digunakan melalui metode deskriptif. Sementara teknik pengumpulan datanya menggunakan studi pustaka. Hasil penelitian membuktikan bahwa komponen komponen pendidikan karakter yang dilaksanakan secara terintegrasi memberikan efek yang positif terhadap perubahan perilaku dan sikap siswa terutama karakter jujur. Dampak dari hasil kajian ini adalah bahwa penanaman nilai karakter harus sudah dibiasakan sejak dini sehingga anak sudah terbiasa dengan hal hal yang baik sejak dini.
\end{abstract}

Kata Kunci: strategi pendidik; karakter jujur; anak usia dini

\begin{abstract}
Two or three year- old children are prone to behave dishonestly as their essential misbehaviour such as they are unable to take care of the school's toys as well as they take the school's stuffs. This condition will become their personal character if there is no further action from their neighbourhood. The effective character building as the proper parameter contributes to instil the students' personalities for the next levels of education. Therefore, the aim of this research is to analyze and describe the components of educating the students to have a good character or honesty. It covers a qualitative research in which the researcher employs a number of relevant theories from the experts as descriptive method. Meanwhile, the data were gathered from reviewing the relevant studies. The study reveals that the integrated components of character education contribute to providing positive impact towards the change of pre school-students' attitudes particularly having honesty.
\end{abstract}

Keywords: teachers' strategy; honesty; pre-school students.

Copyright (c) 2021 Yoyo Zakaria Ansori

$\triangle$ Corresponding author:

Email Address : al.anshory0928@unma.ac.id (Majalengka, Indonesia)

Received 19 March 2021, Accepted 19 April 2021, Published 24 April 2021 


\section{PENDAHULUAN}

Bangsa Indonesia memproklamasikan kemerdekaannya pada tanggal 17 Agustus 1945. Pada masa itu pendiri bangsa merumuskan visi bahwa untuk kemajuan bangsa ini ada beberapa tantangan besar yang dikemudian hari harus dipersiapkan oleh generasi muda. Cita-cita pertama adalah mendirikan negara berdaulat yang terbebas dari intimidasi penjajah. Kedua, membangun bangsa yang berkeadilan sosial. Ketiga, membangun karakter yang baik. Ketiga cita cita tersebut merupakan komitmen bangsa Indonesia karena secara terinci terdapat pada konsep bernegara dan pembangunan karakter manusia seutuhnya Pada implementasinya upaya untuk membangun bangsa dan membangun karakter lebih terlambat dibandingkan dengan mendirikan negara yang relatif lebih cepat. Padahal pentingnya membangun karakter diutarakan oleh Ir. Soekarno menurutnya Indonesia menjadi bangsa besar, serta berjaya dan memiliki bermartabat manakala bangsa ini dibangun dengan mendahulukan pembangunan karakter (Hariyanto, 2013). Kalau pembangunan karakter dihilangkan, maka siap-siap bangsa Indonesia akan menjadi budak diantara negara lainnya.

Pembinaan karakter pada pendidikan anak usia dini adalah amanat dari Pembukaan UUD 1945 yaitu Pancasila sebagai landasan dasar sekaligus pandangan hidup yang harus terinternalisasi pada semua bidang dalam mewujudkan pembangunan manusia yang berkelanjutan. Pembinaan karakter bangsa masih dipandang sebagai salah satu bidang strategis yang sangat penting sebagai pondasi untuk kehidupan bermasyarakat, berbangsa, dan bernegara. Hal tersebut selaras dengan Kebijakan Nasional Pembangunan Karakter Bangsa dalam mengimplementasikan dari amanat Rencana Pembangunan Jangka Panjang Nasional Tahun 2005-2025. Di tataran praktis Kementerian Pendidikan Nasional telah mengidentifikasi 18 nilai karakter yang mesti ditumbuhkan pada pada peserta didik. Karakter tersebut merupakan nilai utama yang mesti tertanam pada siswa yang bersumber dari agama, Pancasila, budaya dan tujuan pendidikan nasional. Kejujuran merupakan salah satu karakter yang mendesak untuk diwujudkan pada anak usia dini yang berperan dalam mewujudkan cita-cita bangsa. Oleh karena itu penting kiranya bahwa pendidikan karakter merupakan kunci sukes seseorang dan harus dibiasakan sejak dini (Hulukati \& Rahmi, 2020; Ramdhani et al., 2019; Wulandari \& Suparno, 2020). Hal ini dikarenakan karakter jujur merupakan salah satu kunci utama seseorang dalam meraih kesuksesan.

Pentingnya karakter jujur pada anak usia dini dikemukakan oleh beberapa ahli. Pendidikan karakter menjadi kunci dalam membentuk kepribadian manusia seutuhnya sehingga manusia dapat hidup sebagai makhluk sosial dan individu dengan memiliki karakter yang baik (Jusmawati et al., 2020; Lase et al., 2020; M. Christopher, 2016; Suprajogo et al., 2020). Menurut Freud pendidikan usia dini merupakan kunci dalam membentuk kepribadian anak, kegagalan penanaman kepribadian akan membentuk pribadi yang perusak dan bermasalah (Muslich, 2011). Keberhasilan guru dalam membimbing dan mengatasi berbagai permasalahan pada kepribadian di usia dini ikut menentukan keberhasilan anak dalam kehidupannya di masa depan. Pada usia dini perlu dibentuk dan dibina karakter yang berkualitas, karena pada usia ini merupakan masa penting bagi pembentukan karakter seseorang (Rohmah, 2018). Penanaman nilai-nilai karakter sejak dini merupakan proses yang sangat penting dalam membentuk fondasi kepribadian manusia (Tanto et al., 2019). Oleh karena itu menurut (Hakam, 2016). kegagalan dalam menginternalisasi nilai-nilai moral pada usia itu akan berdampak kurang baik bagi kehidupan moral anak dimasa depannya. Pendidikan sejak dini merupakan fase yang sangat tepat bagi pembentukan kepribadian untuk selanjutnya ditanamkan nilai kebaikan dalam diri anak sejak dini (Nuraeni et al., 2019). Dari penjelasan tersebut maka begitu pentingnya peran pendidikan anak usia dini dalam menumbuhkan karakter jujur siswa. Oleh karena itu apabila pada masa usia dininya sudah terbentuk karakter baik maka manakala beranjak dewasa dia akan memiliki prinsip kuat dan tidak akan mudah terhadap godaan dan rayuan yang menggiurkan. Keberhasilan dalam mewujudkan karakter pada usia itu akan menjadi parameter untuk membangun karakter siswa di jenjang pendidikan berikutnya (Ansori, 2020a) 
Pada kenyataannya pada saat ini orang begitu mudah tunduk akan godaan dan rayuan. Pada level bangsa ketidakjujuran nampak berdasarkan laporan dari Transparency International Indonesia (TII) mengungkapkan Indeks Persepsi Korupsi (IPK) Indonesia tahun 2020 berada di skor 37. Turun sebanyak tiga poin dari tahun sebelumnya. Pada saat ini peringkat Indonesia berada di peringkat 102 dari 180 negara Di level Asia Tenggara (ASEAN), Indonesia berada di peringkat lima berada di bawah negara Singapuran dan lainnya. Padahal praktik ketidakjujuran merupakan tanda-tanda kehancuran bagi suatu bangsa (Solan, 2001; M. Christopher, 2016; Sarah et al., 2019). Sementara pada level anak usia dini sikap tidak jujur masih ditemukan seperti tidak terbiasa berkata yang sesungguhnya, mainan miliknya tidak di rawat dengan baik, jika terjadi kesalahan anak belum mau mengakuinya, jika ada siswa yang lebih baik dia sulit menerimanya sampai dengan mengambil barang yang bukan miliknya (Apriliana \& Setiawati, 2020)

Data-data di atas menunjukan bahwa bangsa ini sedang mengalami krisis moral utamanya karakter kejujuran. Fenomena itu juga menunjukkan bahwa pendidikan karakter yang diajarkan belum tertanam dalam diri siswa dan mereka bertindak tidak sesuai dengan apa yang diucapkannya (Komalasari, 2012). Hal ini kuat diduga karena pendidikan hanya berorientasi pada kecerdasan intelektual, menghindari nurani serta mengabaikan nilai-nilai luhur karakter (Zubaidi, 2011; Warsito \& Widodo, 2018) . Padahal menurut Bloom (1974) ada tiga ranah yang harus dikembangkan guru dalam kegiatan pembelajaran di sekolah yaitu ranah kognitif, afektif, dan psikomotor. Untuk itu supaya tidak terjadi kekeliruan pada praktik pendidikan maka pendidikan karakter harus sesuai dengan perkembangan usianya. Sekolah harus mampu memberikan fasilitas dalam melakukan perubahan, tak diragukan berperan besar dalam menumbuh kembangkan sikap siswa ke arah yang jauh lebih baik, melalui karakter jujur kita dapat merubah sikap bangsa menjadi lebih baik.

Pembangunan karakter di sekolah, kejujuran menjadi pondasi yang harus dimiliki oleh siswa Indonesia saat ini. Hasil survei menunjukan bahwa kualitas yang menentukan seseorang diantaranya adalah kejujuran (Posner et al., 2011). Tanpa kejujuran keutamankeutamaan sikap lainnya kehilangan nilai. Menjadi pribadi yang baik terhadap orang lain, tanpa kejujuran, adalah kemunafikan. Oleh karena itu menurut (Lickona, 2009)kejujuran adalah nilai yang harus dicontohkan agar tertanam dalam nurani siswa. Jujur yang dimaksud seperti jujur yaitu tidak berbuat curang, atau mengambil hak orang lain. Sementara kejujuran dimaknai sebagai upaya menjunjung tinggi kebenaran, ikhlas dan tidak berhong serta tidak menjerumuskan orang lain (Hariyanto, 2013).

Menyiasati hal itu, maka perlu strategi bagi pendidik untuk menumbuhkan dan melahirkan karakter anak yang tidak hanya cerdas (smart) namun pula berperilaku jujur (honesty). Khususnya di Indonesia pada saat ini dinilai oleh banyak kalangan implementasi pendidikan dalam menumbuhkan kepribadian yang cerdas tidak ada masalah, namun dinilai kurang berhasil dalam membangun karakter siswa yang memiliki akhlak mulia (jujur). Karena karakter tidak terbatas pada aspek pengetahuan, bahaya persepsi guru manakala karakter hanya pengetahuan. Menurut Roosevelt kalau karakter hanya orientasinya kecerdasan (pengetahuan) tanpa moral maka akan melahirkan ancaman bagi masyarakat (Ansori, 2020b). Sementara menurut Covey menjelaskan akan bahayanya sedikit pengetahuan, tandap didasai nilai karakter maka akan hilangnya nilai luhur bangsa itu (Posner et al., 2011).

Dengan demikian menumbuhkan nilai-nilai luhur karakter yang diberikan sejak usia dini sangat penting karena merupakan pondasi kuat bagi pembentukan tatanan kehidupan masyarakat yang maju, berbudaya, dan berakhlak mulia (Andriani, 2012; Mischo et al., 2014). Pendapat lain menjelaskan bahwa karakter yang berkualitas kuat dan kokoh pada diri anakanak perlu ditanamkan dan dibentuk serta dikembangkan manakala anak berada pada fase usia dini (Aulina, 2013; Riati, 2016; Lickona, 2009), karena pada itu merupakan masa terbentuknya karakter seseorang. Kegagalan penanaman karakter pada usia dini akan berdampak kurang baik pada masa dewasa kelak. 
Atas dasar pentingnya karakter jujur itulah, maka penting kiranya untuk mengkaji lebih dalam mengenai strategi bagi guru untuk menumbuhkan karakter jujur bagi siswa anak usia dini. Oleh karenanya peneliti berupaya untuk melahirkan panduan dan komponen komponen mendidik siswa agar pada praktinya tidak salah langkah sehingga harapan untuk melahirkan perilaku siswa yang good and smart dapat terwujud pada pendidikan anak usia dini.

\section{METODOLOGI}

Untuk keberhasilan dalam penelitian ini, pada praktiknya peneliti banyak mengambil teori teori dari para peneliti terdahulu tentang komponen-komponen untuk membentuk karakter siswa yang jujur untuk selanjutnya diadaptasikan dengan karakteristik anak usia dini. Sehingga penelitian ini bertujuan untuk mendeskripsikan dan menganalisa tentang komponen pendidikan karakter untuk mewujudkan anak yang memiliki karakter baik (jujur) namun pula cerdas. Untuk keberhasilan dalam penelitian ini peneliti banyak mengambil grand theorynya Lickona dari buku Educating For Character, Journal of Moral Education, jurnal nasional pendidikan anak usia dini, dan buku. Selanjutnya peneliti berupaya memahami makna dari teori terdahulu untuk selanjunya dikaji secara interpretatif menurut pendapat peneliti sendiri dengan tidak menggunakan kuntifikasi atau perhitungan statistik .

Pendekatan kualitatif dipilih dengan dasar agar dapat memberikan gambaran yang komperhensif dan merupakan upaya peneliti dalam memahami aspek yang menjadi kajian dalam pandangan dari penulis (Aspers \& Corte, 2019). Karena itu pendekatannya bersifat mendalam dan tanpa melibatkan perhitungan statistik (Bansal et al., 2018). Peneliti menggunakan metode deskriptif. Metode penelitian deskriptif suatu proses penelitian yang memiliki tujuan untuk mendeskripsikan atau mengambil suatu fenomena yang diamati oleh sesorang (Lambert \& Lambert, 2012). Sementara teknik untuk mengambil datanya menggunakan studi pustaka karena penelitian ini memiliki korelasi dengan nilai, budaya, dan norma yang berkembang di masyarakat, Studi kepustakaan memiliki korelasi dengan kajian teoritis dan referensi lain yang berkaitan dengan nilai, budaya serta norma kajian literatur ini dipandang penting dikarenakan penelitian tidak akan lepas dari literatur-literatur ilmiah hasil penelitian dari peneliti terdahulu (Sugiyono, 2014). Alur penelitiannya sebagaimana pada gambar 1 .

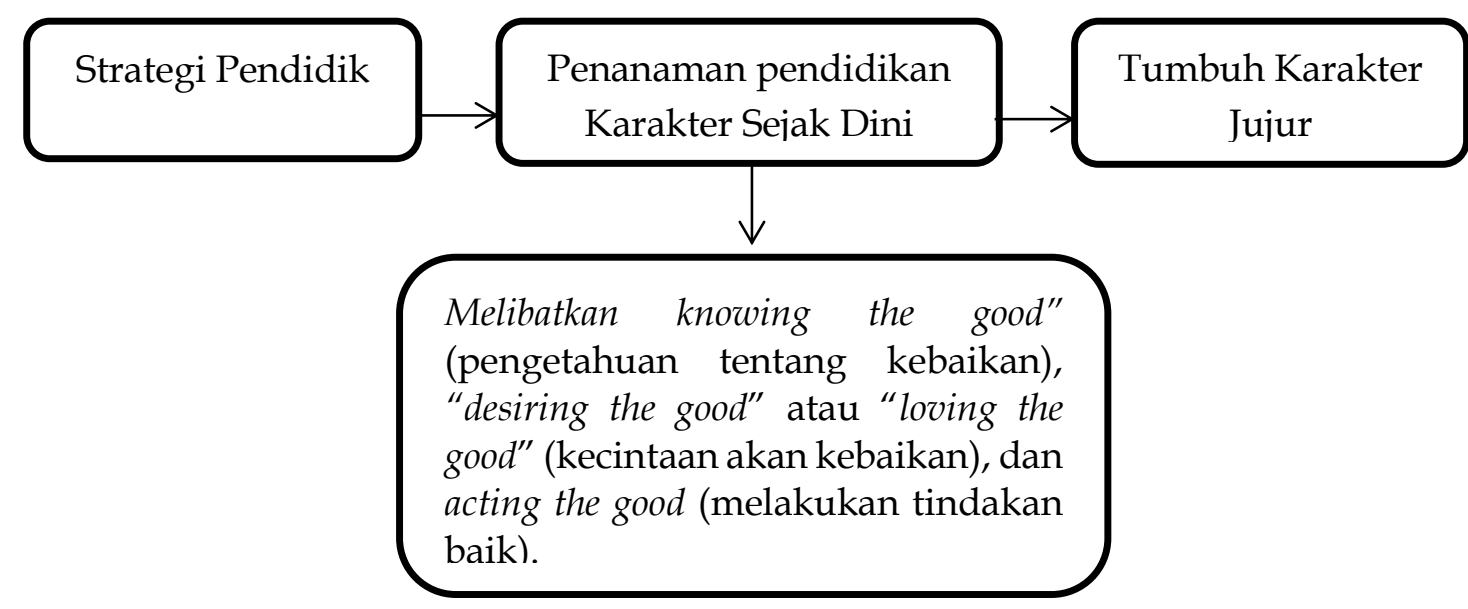

Gambar 1. Alur Penelitian

\section{HASIL DAN PEMBAHASAN}

Dalam UU Sisdiknas tahun 2003 pasal 28 ayat 1, pada rentang kategori usia 0-6 tahun dikategorikan sebagai anak usia dini. Pertumbuhan dan perkembangan pada usia ini mengalami akumulasi yang sangat pesat baik dari fisik maupun psikis. Menurut Piaget (Santrock \& Santrock, 2007) sensorymotor (0 - 2 tahun) sampai fase perkembangan pra 
operasional (2- 7 tahun) termasuk kedalam perkembangan kognisi. Ciri khas yang paling nampak pada fase tersebut adalah anak senang meniru dan menyerap perilaku orang disekelilingnya. Sementara pada usia tersebut anak sedang ada pada masa pertumbuhan baik secara fisik maupun secara mental (Nurmalitasari, 2015). Pada fase ini, anak sedang dalam masa pertumbuhan dan perkembangan yang sangat pesat baik secara emosional, intelektual, kepribadian, bahasa, dan moral. Pada usia ini merupakan momentum yang paling tepat untuk menumbuhkembangkan nilai-nilai karakter seperti kejujuran berdasarkan komponen komponen pendidikan karakter di sekolah (Lickona, 2009) sebagaimana Gambar 2 berikut:

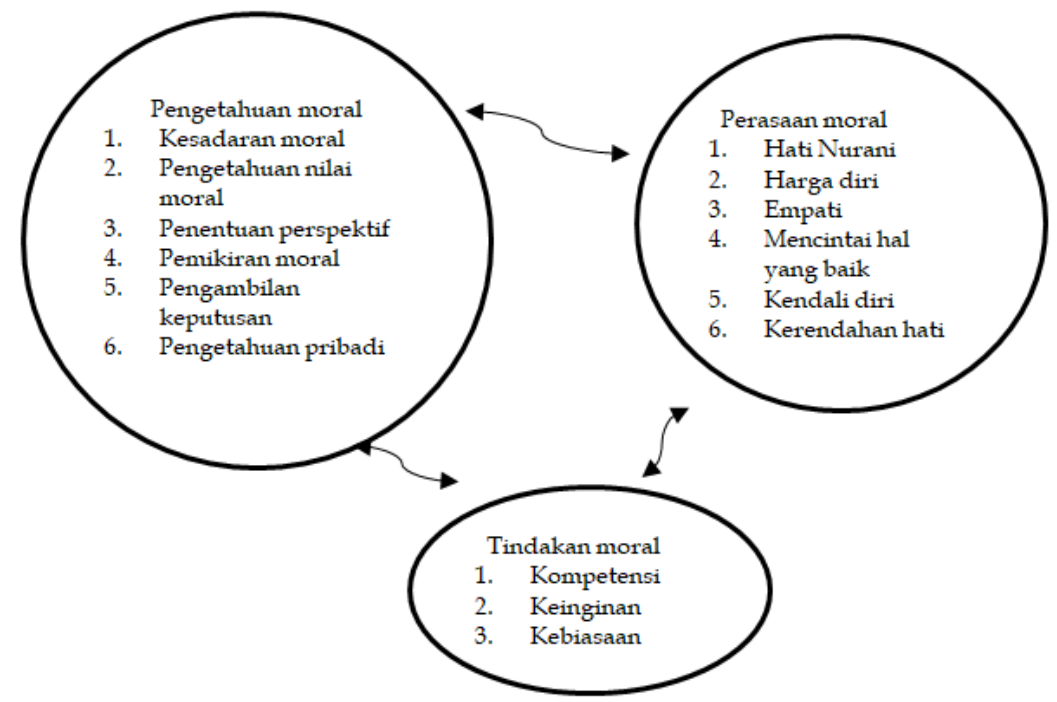

Gambar 2. Komponen Pendidikan Karakter

Berdasarkan komponen pada gambar 2, maka strategi untuk mewujudkan siswa berperilaku jujur dikembangkan melalui tiga tahapan yaitu tahap pengetahuan (knowing), tahap keyakinan (feeling) dan tahap pelaksanaan (acting). Pada tahap pengetahuan (knowing), peran guru secara terus menerus dan terintegrasi menanamkan nilai kejujuran melalui pembelajaran. Materi yang disampaikan contohnya bisa tentang apa yang dimaksud dengan jujur? Bagaimana indikator perbuatan jujur? mengapa manusia mesti bertindak jujur? dan apa manfaat jujur dan konsekuensi jika seseorang tidak jujur?. Hal itu sangat diperlukan untuk mengisi kognisi siswa, karena pada saat ini masih ada anak-anak yang masih berkata dan bertindak tidak jujur dalam kehidupan sehari-hari seringkali mereka berbohong untuk tujuan menyembunyikan perilaku mereka sendiri yang salah (Newton et al., 2000; Wilson \& Pipe, 1989). Berdasarkan penelitian perilaku berbohong anak dapat ditemukan pada usia dua sampai tiga tahun. usia dua dan tiga tahun anak bisa berbohong untuk menyembunyikan lokasi mainannya yang tersembunyi (Chandler, n.d.). Sementara menurut menunjukkan bahwa pada usia dua tahun anak bisa berbohong melalui pernyataan verbal yang tidak benar. Pendapat yang lain disampaikan bahwa Anak-anak seusia tiga tahun telah dapat melakukan kebohongan yang disengaja dan bersifat sederhana (John et al., 2018)

Untuk memberikan pengetahuan tentang moral (moral knowing), metodenya mesti menyesuaikan dengan perkembangan anak yaitu dengan cara belajar sambil bermain karena bermain bagi anak memberikan pandangan belajar tetapi menyenangkan sekaligus juga menghibur. Pembelajaran yang sejati muncul dari kebebasan anak-anak untuk memilih kegiatan yang ia senangi (Datnow \& Park, 2018; Lai \& Zheng, 2018), Bermain adalah aktivitas yang menjadi pilihan diri sendiri oleh anak karena dirasa permainan tersebut akan memberikan nuansa yang menyenangkan, bukan karena hadiah atau pujian (Semiawan, 2008). Dengan bermain, seluruh potensi anak dapat ditingkatkan. Bermain tidak hanya memberikan kepuasan jika dimaknai lebih lanjut bermain menjadikan sarana dalam menanmkan nilai karakter pada anak tersebut (Wiwik Pratiwi, 2017). Oleh karena itu metode 
belajar di pendidikan anak usia dini bisa dilakukan dengan beragam cara seperti dongeng, bernyanyi, berdarma wisata, bermain peran, resitasi, maupun melalui latihan. Metode tersebut tentunya mesti dikemas dengan bermain, karena dengan bermain maka anak akan bereksplorasi secara bebas sehingga anak menemukan hal-hal baru. Melalui permainan maka dampak bagi potensinya akan berkembang secara optimal, baik potensi fisik maupun potensi psikis.

Setelah memberikan pembelajaran tentang pengetahuan moral, maka strategi selanjutnya adalah menanamkan perasaan tentang moral. Perasaan tentang moral (Moral feeling) merupakan ranah yang berkaitan dengan penguatan aspek emosi sekaligus sebagai sumber energi dari diri anak untuk bertindak sesuai dengan prinsip-prinsip moral. Agar anak bertindak sesuai dengan prinsip moral maka perlu ada penguatan yang berhubungan dengan bentuk-bentuk sikap yang harus dirasakan oleh anak, yaitu hati nurani (conscience), harga diri (self esteem), empati (empathy), cinta kebenaran (loving the good), kendali diri (self control), kerendahan hati (humility). Upaya untuk menumbuhkan moral feeling pada siswa dengan cara membangkitkan kesadaran nurani akan pentingnya komitmen melaksanakan nilai-nilai moral. Beberapa penelitian telah banyak yang melibatkan moralitas dan pengembangan hati nurani, nurani berkaitan dengan tingkat ketidaknyamanan perasaan anak atau rasa bersalah setiap berbuat pelanggaran (Abulizi et al., 2017; Malti et al., 2019)

Hal ini menjelaskan bahwa pengetahuan tidaklah cukup untuk menumbuhkan karakter anak namun pengetahuan kebaikan tersebut mesti menginternalisasi pada nurani anak (Abulizi et al., 2017; Malti et al., 2019). Sebagai contoh untuk menanamkan perilaku disiplin pada siswa dengan dengan datang tepat waktu ke sekolah, maka guru harus menumbuhkan rasa bersalah, malu, dan tidak empati manakala siswa datang terlambat ke sekolah. Keyakinan perasaan kebenaran (moral feeling) akan menjadi modal bagi siswa sekaligus kontrol internal yang paling efektif. Disamping kontrol internal, perlu juga pengawasan kontrol eksternal. Kontrol orangtua merupakan pengawasan eksternal yang juga dapat menjadi dimensi penting, gaya pengasuhan orang tua berpengaruh besar pada perilaku kejujuran anak-anak. Kontrol orangtua ditandai dengan penegakan disiplin yang tegas berbasis moral, mengetahui perkembangan karakteristik anak, dan aturan bagi kegiatan dan perilaku anak. Bentuk pengawasan dari orang tua melalui kegiatan bimbingan serta diarahkan untuk mematuhi aturan-aturan sosial dalam berperilaku (Barber et al., 2005; Grolnick \& Pomerantz, 2009). Kontrol orang tua sangat diperlukan karena dapat mempengaruhi kinerja kognitif anak.

Sementara moral action merupakan sarana dalam mewujudkan moral tersebut. Rumus untuk mendorong seseorang berbuat baik (act morally) adalah melalui tiga dimensi dari karakter yaitu kompetensi (competence), keinginan (will), dan kebiasaan (hubit) (Megawangi, 2004). Terintegrasinya ketiga aspek tersebut menjadikan siswa terbiasa untuk berperilaku baik, sehingga ia menjadi terbiasa pula melakukan perbuatan baik dan akan merasa bersalah kalau tidak melakukan perbuatan baik, Perlu adanya keteladanan dalam menanamkan ketiga aspek tersebut agar dapat ditiru oleh anak sejak usia dini. Pemberian ganjaran (reward) dapat dilakukan dengan memberikan reward terhadap individu-individu yang berbuat jujur sementara hukuman dapat dilakukan kepada individu yang berperilaku tidak jujur, namun hendaknya hukuman diberikan sesuai dengan tingkat resiko dari perbuatan ketidakjujurannya. Jika perbuatan jujur itu sudah tertanam dalam diri siswa maka jika dia tidak melakukan kejujuran maka akan merasa bersalah.

Aspek lain sebagai bagian dari moral action adalah keteladanan guru. Keteladanan merupakan kunci yang paling penting dalam menanamkan sifat kejujuran. Keteladanan adalah sikap memberikan contoh yang baik kepada anak. Melalui keteladanan karakter jujur akan mudah di terapkan anak, karena pada usia dini sifat anak untuk mencontoh sangat tinggi. Tahap keteladanan dalam pendidikan karakter merupakan tahap awal yang artinya siswa harus belajar moral dan karakter melalui percontohan orang-orang disekelilingnya, dan dalam mencontoh diperlukan keteladanan yang baik, oleh karenanya guru dituntut untuk 
menjadi panutan yang mesti memiliki nilai moral karena akan di contoh oleh siswanya (Hakam, 2016).

Dengan demikian untuk mewujudkan siswa yang berkarakter jujur maka pendidikan karakter dalam pelaksanaannya harus melibatkan seluruh aspek yaitu aspek "knowing the good" (pengetahuan tentang kebaikan), "desiring the good" atau "loving the good" (kecintaan akan kebaikan), dan acting the good (melakukan tindakan baik). Untuk mewujudkan pribadi siswa yang jujur yaitu dengan semua aspek tersebut dipandang telah berhasil dalam membangun karakter anak (Megawangi, 2004). Dengan knowing the good anak akan terbiasa dengan berpikir hal baik. Reasoning the good anak akan tahu alasan dalam berbuat kebaikan itu, Misalnya sifat jujur dalam hal ini anak harus tau alasan mengapa kejujuran itu penting, dengan feeling the good adanya perasaan dalam membangun kebaikan dan acting the good yaitu karakter jujur yang sudah tertanam dalam diri anak.

Dalam praktiknya guru dituntut berperan aktip untuk mewujudkannya penanaman nilai karakter itu (Ansori, 2018). Tanpa nilai nilai kebaikan mustahil manusia akan mendapatkan suatu kebahagiaan dan tanpa nilai kebaikan pula seluruh umat manusia tidak dapat menuju perkembangan dunia yang lebih bermartabat (Lickona, 2009). Oleh karena itu kemampuan guru dalam menanamkan nilai kejujuran bagi anak usia dini merupakan keharusan yang tidak boleh dihindari (Ananda, 2017), karena dengan kejujuran dekat dengan kebaikan, dan kebaikan akan mengantarkan ke surga.Dalam hadits Rusulullah saw. bersabda: "Hendaklah kalian jujur (benar) karena kejujuran mengantarkan kebaikan, dan kebaikan akan mengantarkan ke surga. Orang yang jujur akan di catata oleh Allah swt. dan jauhilah kedustaan, karena dusta menghantarkan pada kejahatan yang akan membawamu ke neraka, dan akan diberikan label sebagai pendusta (HR. Bukhori). Peran pendidik yang penting dalam menumbuhkan karakter hal ini sesuai dengan penelitian (Sultonurohmah, 2017; Suriansyah, 2015). Menyimpulkan bahwa perlu sinergitas untuk menanamkan karakter pada anak.

\section{SIMPULAN}

Sikap jujur merupakan karakter yang akan membawa bangsa ini menuju pada kemajuan. Dilihat dari konteks pembangunan karakter di sekolah, kejujuran menjadi menjadi karakter yang pentingpada anak karena hakekatnya anak sebagai pewaris pembangunan masa depan. Pada saat ini yang dibutuhkan bangsa bukan hanya hanya siswa yang memiliki karakter smart (pandai) namun juga berkarakter good (baik). Untuk mewujudkannya maka pendidikan karakter dalam pelaksanaannya harus melibatkan seluruh aspek yaitu aspek "knowing the good" (pengetahuan tentang kebaikan), "desiring the good" atau "loving the good" (kecintaan akan kebaikan), dan acting the good (melakukan tindakan baik).

\section{UCAPAN TERIMA KASIH}

Ucapan terimakasi kepada Rektor Universitas Majalengka dan Dekan FKIP yang selalu menyemangati penulis dalam hal menerbitkan karya tulis yang relevan dengan bidang keilmuwan.

\section{DAFTAR PUSTAKA}

Abulizi, X., Pryor, L., Michel, G., Melchior, M., Van Der Waerden, J., \& Group, E. M.--C. C. S. (2017). Temperament in infancy and behavioral and emotional problems at age 5.5: The EDEN mother-child cohort. PLoS One, 12(2), e0171971. https://doi.org/10.1371/journal.pone.0171971

Ananda, R. (2017). Implementasi Nilai-nilai Moral dan Agama pada Anak Usia Dini. Jurnal Obsesi: Jurnal Pendidikan Anak Usia Dini, 1(1), 19. https://doi.org/10.31004/obsesi.v1i1.28

Andriani, T. (2012). Permainan Tradisional Dalam Membentuk Karakter Anak Usia Dini. Jurnal Sosial Budaya, 9(1), 121-136. 
Ansori, Y. Z. (2018). Menumbuhkan Karakter Baik Melalui Peranan Guru Di Sekolah. Jurnal Cakrawala Pendas, 4(2). https://doi.org/10.31949/jcp.v4i2.1497

Ansori, Y. Z. (2020a). Penguatan karakter disiplin siswa melalui peranan guru di sekolah dasar. Jurnal Elementaria Edukasia, 3(1), 126-135.

Ansori, Y. Z. (2020b). Penguatan Karakter Religius Siswa Melalui Pembelajaran Sains Bernuansa Pendidikan Nilai. BIO EDUCATIO: (The Journal of Science and Biology Education), 5(1), 57-64. https:// doi.org/10.31949/be.v5i1.2123

Apriliana, A. C., \& Setiawati, T. (2020). THE EFFECTIVENESS OF BIBLIOTHERAPY IN IMPROVING. Widyagogik, $\quad 8('), \quad 16-25$. https:// doi.org/https:// doi.org/10.21107/widyagogik.v8i1.8677 Received

Aspers, P., \& Corte, U. (2019). What is qualitative in qualitative research. Qualitative Sociology, 42(2), 139-160. https:// doi.org/10.1007/s11133-019-9413-7

Aulina, C. N. (2013). Penanaman Disiplin Pada Anak Usia Dini. PEDAGOGIA: Jurnal Pendidikan, 2(1), 36. https:// doi.org/10.21070/pedagogia.v2i1.45

Bansal, P. T., Smith, W. K., \& Vaara, E. (2018). From the editors new ways of seeing through qualitative research. Academy of Management Journal, 61(4), 1189-1195. https:// doi.org/10.5465/amj.2018.4004

Barber, B. K., Stolz, H. E., \& Olsen, J. A. (2005). Parental support, psychological control, and behavioral control: assessing relevance across time, culture, and method. Monographs of the Society for Research in Child Development, 70(4), 1-137. https:// doi.org/10.1111/j.1540-5834.2005.00365.x

Bloom, B. S. (1974). Taxonomy of Educational Objectives. David McKay Company.

Chandler, M. (n.d.). Fritz, \& Hala, S.(1989). Small-scale deceit: Deception as a marker of two-, three-, and four-year-olds' early theories of mind. Child Development, 60, 1263-1277. https://doi.org/10.2307/1130919

Datnow, A., \& Park, V. (2018). Professional collaboration with purpose: Teacher learning towards equitable and excellent schools. Routledge. https:// doi.org/10.4324/9781351165884

Grolnick, W. S., \& Pomerantz, E. M. (2009). Issues and challenges in studying parental control: Toward a new conceptualization. Child Development Perspectives, 3(3), 165-170. https:// doi.org/10.1111/j.1750-8606.2009.00099.x

Hakam, K. A. (2016a). Pendidikan Karakter di Sekolah Dasar. UPI Press.

Hakam, K. A. (2016b). Pendidikan Karakter di Sekolah Dasar. UPI.

Hariyanto, M. S. (2013). Konsep dan Model Pendidikan Karakter. PT. Remaja Rosdakarya.

Hulukati, W., \& Rahmi, M. (2020). Instrumen Evaluasi Karakter Mahasiswa Program Pendidikan Guru Pendidikan Anak Usia Dini. Jurnal Obsesi : Jurnal Pendidikan Anak Usia Dini, 4(2), 851. https:// doi.org/10.31004/obsesi.v4i2.468

John, A., Glendenning, A. C., Marchant, A., Montgomery, P., Stewart, A., Wood, S., Lloyd, K., \& Hawton, K. (2018). Self-harm, suicidal behaviours, and cyberbullying in children and young people: Systematic review. Journal of Medical Internet Research, 20(4), e129. https:// doi.org/10.2196/jmir.9044

Jusmawati, Rusdinal, \& Barlian, E. (2020). Exploration of the Honest Character of the Orphanage and Its Implications for Strengthening Character Education. Proceedings of the 2nd International Conference Innovation, 504(ICoIE), 232-235. https://doi.org/10.2991/assehr.k.201209.225

Komalasari, K. (2012). The effect of contextual learning in civic education on students' character development. The Asia Pacific Journal of Educators and Education (Formerly Known as Journal of Educators and Education), 27(1), 1-17.

Lai, C., \& Zheng, D. (2018). Self-directed use of mobile devices for language learning beyond the classroom. ReCALL, 30(3), 299-318. https://doi.org/10.1017/S0958344017000258

Lambert, V. A., \& Lambert, C. E. (2012). Qualitative descriptive research: An acceptable design. Pacific Rim International Journal of Nursing Research, 16(4), 255-256. 
DOI: 10.31004/obsesi.v6i1.1208

Lase, F., Nirwana, H., Neviyarni, N., \& Marjohan, M. (2020). The Differences of Honest Characters of Students Before and After Learning with A Model of Learning of Intelligent Character. Journal of Educational and Learning Studies, 3(1), 41. https://doi.org/10.32698/0962

Lickona, T. (2009). Educating for character: How our schools can teach respect and responsibility. Bantam.

M. Christopher, A. M. L. S. (2016). Theory of mind training causes honest young children to $\begin{array}{llll}\text { lie. Physiology \& Behavior, 100-106. } & \text { 176(1), }\end{array}$ https://doi.org/10.1177/0956797615604628.Theory

Malti, T., Zhang, L., Myatt, E., Peplak, J., \& Acland, E. L. (2019). Emotions in contexts of conflict and morality: Developmental perspectives. In Handbook of emotional development (pp. 543-567). Springer. https://doi.org/10.1007/978-3-030-17332-6_21

Megawangi. (2004). Pendidikan Karakter, Solusi yang Tepat Untuk Membangun Bangsa. Indonesia Heritage Foundation.

Mischo, C., Wahl, S., Strohmer, J., \& Wolf, C. (2014). Does Early Childhood Teacher Education Affect Students' Cognitive Orientations? The Effect of Different Education Tracks in Teacher Education on Prospective Early Childhood Teachers' Cognitive Orientations in Germany. Journal of Education and Training Studies, 2(1), 193-206. https://doi.org/10.11114/jets.v2i1.206

Muslich, M. (2011). Pendidikan karakter: menjawab tantangan krisis multidimensional. Bumi Aksara.

Newton, P., Reddy, V., \& Bull, R. (2000). Children's everyday deception and performance on false-belief tasks. British Journal of Developmental Psychology, 18(2), 297-317. https://doi.org/10.1348/026151000165706

Nuraeni, L., Andrisyah, A., \& Nurunnisa, R. (2019). Efektivitas Program Sekolah Ramah Anak dalam Meningkatkan Karakter Anak Usia Dini. Jurnal Obsesi : Jurnal Pendidikan Anak Usia Dini, 4(1), 20. https:// doi.org/10.31004/obsesi.v4i1.204

Nurmalitasari, F. (2015). Perkembangan Sosial Emosi pada Anak Usia Prasekolah. Buletin Psikologi, 23(2), 103. https:// doi.org/10.22146/bpsi.10567

Posner, B. Z., Kouzes, J. M., \& Dixit, V. (2011). The leadership challenge. J Educ Voc Res, 1(1), 1-3.

Ramdhani, S., Yuliastri, N. A., Sari, S. D., \& Hasriah, S. (2019). Penanaman Nilai-Nilai Karakter melalui Kegiatan Storytelling dengan Menggunakan Cerita Rakyat Sasak pada Anak Usia Dini. Jurnal Obsesi: Jurnal Pendidikan Anak Usia Dini, 3(1), 153. https://doi.org/10.31004/obsesi.v3i1.108

Riati, I. K. (2016). Pengaruh Pola Asuh Orangtua Terhadap Karakter Anak Usia Dini. Infantia, 4(2), 8. https://antologi.upi.edu

Rohmah, U. (2018). Pengembangan Karakter Pada Anak Usia Dini (AUD). Al-Athfal : Jurnal Pendidikan Anak, 4(1), 85-102. https:// doi.org/10.14421/al-athfal.2018.41-06

Santrock, J. W., \& Santrock, J. W. (2007). Psikologi Pendidikan edisi kedua. Kencana Prenada Media Group.

Sarah, S., Prasetyo, Z. K., \& Wilujeng, I. (2019). Development of living values (honesty) assessment instrument in learning process. International Journal of Instruction, 12(4), 443-458. https://doi.org/10.29333/iji.2019.12429a

Semiawan. (2008). elajar dan Pembelajaran Prasekolah dan Sekolah Dasar. PT. Index.

Solan, L. (2001). The written contract as safe harbor for dishonest conduct. Chicago-Kent Law Review, 77(1), 87-120.

Sugiyono. (2014). Metode Penelitian Kombinasi. Alfabeta.

Sultonurohmah, N. (2017). Strategi penanaman nilai karakter jujur dan disiplin siswa. AlIbtida, 5(2), 1-21.

Suprajogo, T., Kalida, M., \& Roshonah, A. F. (2020). Anticipation of corruption through literation based honest behaviour learning in early childhood education. International 
$\begin{array}{llll}\text { Journal of Psychosocial Rehabilitation, 24(08), 1307-1319. } & \text {. }\end{array}$ https:/ / doi.org/10.37200/IJPR/V24I8/PR280145

Suriansyah, A. (2015). Strategi kepemimpinan kepala sekolah, guru, orang tua, dan masyarakat dalam membentuk karakter siswa. Jurnal Cakrawala Pendidikan, 34(2). https:// doi.org/10.21831/cp.v2i2.4828

Tanto, O. D., Hapidin, H., \& Supena, A. (2019). Penanaman Karakter Anak Usia Dini dalam Kesenian Tradisional Tatah Sungging. Jurnal Obsesi : Jurnal Pendidikan Anak Usia Dini, 3(2), 337. https:// doi.org/10.31004/obsesi.v3i2.192

Warsito, R., \& Widodo, S. T. (2018). Implementasi Nilai-Nilai Luhur Ajaran Ki Hajar Dewantara Dalam Perkuliahan Pendidikan Pancasila Untuk Mengembangkan Karakter Mahasiswa. PKn Progresif: Jurnal Pemikiran Dan Penelitian Kewarganegaraan, 13(1), 1. https:// doi.org/10.20961/pknp.v13i1.22448

Wilson, J., \& Pipe, M.-E. (1989). The Effects of Cues on Young Children's Recall of. In New Zealand Journal of Psychology (Vol. 18, p. 65fi70).

Wiwik Pratiwi. (2017). Konsep Bermain Pada Anak Usia Dini. Manajemen Pendidikan Islam, $5,106-117$.

Wulandari, A., \& Suparno, S. (2020). Pengaruh Model Problem Based Learning terhadap Kemampuan Karakter Kerjasama Anak Usia Dini. Jurnal Obsesi : Jurnal Pendidikan Anak Usia Dini, 4(2), 862. https:// doi.org/10.31004/obsesi.v4i2.448

Zubaidi. (2011). Desain Pendidikan Karakter. Prenada Media Group. 